\title{
Superexogeneity and the dynamic linkages among international equity markets
}

\author{
Bill B. Francis ${ }^{\text {a,* }}$, Lori L. Leachman ${ }^{\mathrm{b}}$ \\ ${ }^{a}$ Department of Finance, College of Business Administration, University of South Florida, Tampa, \\ FL 33620-5500, USA \\ ${ }^{\mathrm{b}}$ Department of Economics, College of Business Administration, Northern Arizona University, \\ Flagstaff, AZ 86011, USA
}

\begin{abstract}
In this article, we combine the Johansen procedure for cointegration testing with tests of weak exogeneity and invariance in order to ascertain whether a system of equity markets is characterized by superexogeneity. Superexogeneity is rejected for the system comprised of stock indices of the US, UK, Germany and Japan. This finding implies that agents participating in these financial markets are forward looking, all markets are endogenous in our system and the assumption of stability of the asset demand function is questionable. (C) 1998 Elsevier Science Ltd. All rights reserved.
\end{abstract}

JEL classifications: $\mathrm{F} 3, \mathrm{G} 13$

Keywords: Superexogeneity; Cointegration; Forward-looking

\section{Introduction}

The termination of the Bretton Woods system and the increased liberalization of international capital markets which followed, have led to a growing body of research which assesses the linkages and co-movements between international asset markets (see Hamao et al., 1990; Chan et al., 1992; King et al., 1994; Longin

\footnotetext{
* Corresponding author.
} 
and Solnik, 1995). The results of these studies are inconclusive as to the extent of integration among international equity markets. A possible explanation is that, in general, these studies focus on short-term interactions and relationships between markets, while ignoring long-run linkages. The primary purpose of this analysis is to explore the long-term relation(s) among national equity markets and to present new evidence regarding the linkages and co-movements among these markets. Additionally, evidence on the short-run dynamics characterizing these markets is provided.

Empirical research on the relations between international equity markets usually adopts the perspective of the US investor. An implication of this approach is that the findings are useful in shedding light on the international asset demand function for domestic investors. Additional assumptions of these studies are: (a) the demand function is stable over the sample period; (b) all markets are endogenous; and (c) their (markets) adjustments to the relationships characterized by the model are backward-looking in nature. In this article, we emperically test the validity of these assumptions.

Utilizing the procedure of Johansen (1988), we establish the presence of a cointegrating relationship between four national equity markets. We then test for weak exogeneity of each market included in our system. The results of these tests have implications for modeling the long-term demand for international assets and the testing of international pricing theories. Next, the cointegration results are used to develop an error correction model (ECM) which forms the conditional submodel. This submodel is the foundation for tests of invariance and superexogeneity. The invariance results are germane to the stability assumption, while the findings concerning superexogeneity provide evidence on the nature of the adjustment process and the correct interpretation of the model.

\section{Economic background}

Most of the empirical work investigating the relationship between international equity markets focus on short-run relations between markets. Hamao et al. (1990) and Longin and Solnik (1995), to name a few, investigate the interdependence of returns and/or returns volatility across national equity markets. Eun and Shim (1989) and Jeon and von Furstenberg (1990) examine the speed and strength of intertemporal transmission of innovations across major stock exchanges. Articles by Wheatly (1988), Campbell and Hamao (1992), Chan et al. (1992), Korajczyk and Viallet (1992), King et al. (1994) and Bekaert and Harvey (1995), among others, investigate international equity market relations in the context of asset price modeling. In general, the evidence emerging from these studies is that national equity markets exhibit a variety of short-term linkages and interactions and are becoming reasonably well integrated. However, the study by King et al. questions heightened integration. Specifically, they argue that stock markets are not integrated and the perceived increased market integration is only a transitory increase caused by the 1987 crash. 
Another branch of research has investigated long-term co-movements and relationships among national equity markets. Articles by Kasa (1992) and Leachman and Francis (1995), to name a few, employ the procedure of Johansen (1988) for cointegration testing to assess the long-run relationship(s) among international stock markets. Their results indicate that national equity markets possess common long-run equilibrium path(s) or equivalently, common stochastic trends. These findings are therefore consistent with linkages between national equity markets, albeit over a longer time horizon.

The degree and nature of, as well as the time period necessary to establish equity market linkages are important for a variety of reasons. First, in general, the benefits from international portfolio diversification are significantly diminished in an environment characterized by a high degree of integration and co-movements among national stock markets. The finding of increasing ties between national equity markets suggests that the demand function for international assets has, in all likelihood, changed in recent years. Second, the rewards from diversification might still be substantial in a world of integrated markets if investors holding periods are less than the time necessary for markets to adjust to deviations from their equilibrium path. Third and most important for the purposes of this article, market linkages evidenced by cointegration between a system of variables imply a valid ECM.

The ECM has traditionally been interpreted as a backward looking adjustment process characterized by (Granger) causal relationships. However, researchers have recently questioned this interpretation and point out that an error correction representation among a set of variables may result from a forward looking optimization strategy on the part of economic agents (see Engle et al., 1983; Nickell, 1985; Campbell and Shiller, 1988; Engle and Hendry, 1993). Granger causality may or may not characterize such a system. Given that a broad class of international asset pricing models is expectationally based, this interpretation holds theoretical relevance.

The reduced forms of the more conventional backward-looking ECMs and forward-looking expectation models are essentially the same. Nickell (1985) shows that disequilibrium errors may result from rational expectations and forward-looking optimization. Campbell and Shiller (1988) point out that the finding of cointegration and therefore the existence of an ECM between a set of economic variables does not necessarily arise from the adjustment to past disequilibria but may be due to economic agents' forecasts of future changes. In examining the dividend behavior of firms, they question the interpretation (of firms' dividend behavior) of Marsh and Merton (1987) that the ECM representation is a result of firms adjusting dividends so as to reach a desired dividend price ratio. They argue that it is quite possible that prices react to expectations of future dividends. Thus, a valid ECM of a system of stock prices could be interpreted as consistent with the basic present discounted value model (PDV). Hurn and Muscatelli (1992) note that this is another aspect of the observational equivalence of forward-looking and feedback only models. Thus, it is of interest to ascertain whether the ECM, which 
underlies our system of national equity markets, is the result of intertemporal (forward-looking) optimization by economic agents or simply their adjustment to disequilibria. The issue of distinguishing between these two interpretations becomes one of testing for superexogeneity.

In this article we establish the presence of a cointegrating relationship between a system of four major stock market indices; those of the United States (US), United Kingdom (UK), Germany (GER) and Japan (JP). Employing tests developed by Johansen (1992) and Johansen and Juselius (1992) we extend the cointegration research as it relates to international equity markets by testing for weak exogeneity of these stock markets. Additionally, noting that weak exogeneity is neither a necessary nor sufficient condition for structural invariance (see Engle et al., 1983) and that structural invariance, weak exogeneity and consistency form the composite characteristic of superexogeneity, we test for superexogeneity in our model of dynamic adjustments of the markets. Rejection of superexogeneity is consistent with the hypothesis that the ECM, which corresponds to our cointegration results, is forward looking. Our methodology follows the framework suggested by Engle and Hendry (1993).

Results indicate that the system of markets share one cointegrating vector or equivalently three common stochastic trends. None of the four markets is weakly exogenous to the long run equilibrium path. Additionally, structural invariance is clearly rejected for the UK and JP markets. These results necessitate rejection of superexogeneity for all four markets included in our system. They support the foundation of a class of asset pricing models based on expectations and imply that the critique of Lucas (1976) may have relevance for international equity markets as asset demand functions may vary with regime changes.

The remainder of this article proceeds as follows. Section 3 presents a brief discussion of the concepts of weak exogeneity, consistency and invariance. These concepts are then related to expectation formation, the Lucas critique and financial modeling. Section 4 briefly discusses the data and outlines the methodology. In Section 5, the cointegration results and weak exogeneity tests are presented. Invariance and superexogeneity findings are discussed in Section 6. Section 7 concludes.

\section{Superexogeneity}

Superexogeneity of a variable within a set of variables has a number of implications. First, if a variable, say $x_{t}$, is superexogenous then analysis of a related set of variables can be undertaken without having to specify how $x_{t}$ is determined. In other words, it can be treated as if it is set outside the model, simplifying analysis and boosting robustness. Furthermore, superexogeneity implies that the generating process of $x_{t}$ is invariant to either the sample or the forecast periods. Thus, regime changes do not affect the parameters of the conditioning relationship. In such an environment the Lucas critique is not relevant so conditional policy analysis is as 
accurate as possible. Finally, superexogeneity of $x_{t}$ implies that the conditional variable is determined in the context of a more conventional backward-looking model.

Given our system of variables, superexogeneity tests allow us to present indirect evidence concerning a broad class of asset pricing models. The most basic model in finance is the present value formulation in which stock prices are a function of expected future dividends. This model is derived from rational expectations behavior. In fact, Dow and Gorton (1995) identify a forward-looking or 'prospective' role, as they term it, for stock prices which enhances economic efficiency. Therefore acceptance of superexogeneity in our system of stock price indices would be inconsistent with the forward-looking nature of the model.

Superexogeneity requires three conditions:

1. Weak exogeneity of the conditioning variable, $x_{i}$. The variable $x_{i}$ is defined as weakly exogenous for estimating a set of parameters $\delta$, if inference on $\delta$ conditional on $x_{i}$ involves no loss of information. In that the joint density of $\left(y_{t}\right.$, $x_{t}$ ) can be rewritten as the product of $y_{t}$ conditional on $x_{t}$ times the marginals of $x_{t}$, weak exogeneity of $x_{t}$ implies that the moments of $x_{t}$ add nothing to the analysis (see Engle et al., 1983 for a more complete discussion). In other words, $\mu^{x}, \sigma^{x x}$ and $\sigma^{x y}$ (the mean, variance and covariance, respectively) do not enter the conditional model. In addition, if $y_{t}$ does not Granger cause $x_{t}$, then $x_{t}$ is strongly exogenous.

2. Consistency of the basic parameters $\delta$. This is a fundamental property of all good econometric models. In the current context it produces a homoscedastic conditional model if $\sigma_{t}^{y y}=\omega+\delta \sigma_{t}^{x x}$.

3. Invariance of the parameters $\delta$ to events which occasion changes in the processes generating $x_{t}$. Weak exogeneity of $x_{t}$ sustains conditional inference within a given regime. Invariance serves a similar function across regimes. While it may be true that parameters of interest as well as nuisance parameters are variation free over any given regime, they may change between regimes. Invariance implies that they do not. Thus, the invariance property is an attempt to distinguish the deep, structural relationships from the interdependent, fluid relationships that characterize economic models.

Tests of weak exogeneity provide the foundation upon which to build an asset demand function within a given regime. They provide an empirical basis for fixing certain variables and determining what the parameters of interest are. Furthermore, weak exogeneity tests address the assumption of endogeneity of all markets in the international asset demand function.

Structurally invariant conditional models are necessary to assure the reliability of policy simulations and control exercises. Changes in the distributions of the conditioning variables have no effects on the conditional submodel in such a context. Thus, conditional forecasts of the endogenous variable are as accurate as possible given the model. This condition is at the heart of the Lucas critique and rational expectations debate. Lucas argues that invariance is unlikely in that 
economic agents' expectation mechanisms are altered by policy changes. The moments of the conditioning variables are affected and this in turn alters the parameters of interest. In this context the parameters do not represent autonomous behavioral relationships. Therefore false superexogeneity assumptions are likely to produce predictive failures in the conditional models.

Stock markets of the major industrialized countries have individually and collectively experienced a number of regime changes over the post-Bretton Woods era. Clearly the period following the dismantling of the gold standard and fixed exchange rates also corresponded with incremental and, in certain cases, major liberalization efforts directed at financial markets. For example, in the US the Deregulation and Monetary Control Act was passed in 1980 enabling depository institutions to offer discount brokerage services thereby broadening the access of the general public to the stock markets. In 1986 foreign issuers who were in compliance with home country laws were allowed on the US stock exchanges, the 'Big-Bang' occurred in Great Britain and the Tokyo Stock Exchange admitted its first foreign members (see Mussa and Goldstein, 1993 for a more complete listing of financial markets liberalization). Additionally, with regards to the foreign exchange market, the European Monetary System (EMS) was established in 1979, foreign exchange trading was liberalized in Japan in 1984 and the Plaza and Louvre Accords were ratified in 1985 and 1987, respectively. While events such as these were not explicitly directed at national equity markets, Leachman and Francis (1995) provide evidence that intervention by central banks in the foreign exchange market can have substantive effects on national equity markets through the effect of exchange rates on domestic prices. Therefore tests of invariance will allow us to provide evidence on whether events such as these have affected the relationships characterizing our system of markets. This, in turn, will provide evidence as to the validity of the assumption that the underlying asset demand function is stable. Furthermore, these tests will allow us to address the issue of the Lucas critique and its relevance to national, as well as international, policy formulation efforts that may affect international financial markets. ${ }^{1}$

Tests of the composite characteristic superexogeneity in our system of four national equity markets should provide evidence concerning the validity of expectations based international asset pricing models. That is, to the extent that stock prices of national equity markets represent the present discounted value of expected future dividends, a finding that national equity markets are not superexogenous would be consistent with the existence of an international asset pricing model.

\footnotetext{
${ }^{1}$ Recently, Longin and Solnik (1995) provided evidence that the correlations across equity markets are not constant. Although presenting preliminary evidence that economic variables, such as dividend yield and interest rates may be a cause of non-constant correlation they did not explicitly address the superexogeneity issue. Thus, this study extends the analysis of Longin and Solnik by suggesting that changes in regimes are a possible cause for non-constant correlation.
} 


\section{Data and methodology}

\subsection{The data}

The data utilized in this study are from Morgan Stanley Capital International. Monthly data on the national stock indices of GER, JP, UK and the US covering the period from January 1974 to August 1990 are employed. ${ }^{2}$ These indices are end-of-month value-weighted and are calculated with dividend reinvestment. In addition cross-listed securities are netted out. All stock indices have been converted to real US dollars using end-of-month exchange rates and the consumer price index.

\subsection{Weak exogeneity}

The approach by Johansen (1988) and Johansen and Juselius (1990, 1992) for cointegration testing provides the starting point for tests of long-run weak exogeneity as well as superexogeneity in our system of variables. The cointegration approach is advantageous on several accounts. First, it allows us to determine the number of long-run equilibrium relationships or equivalently the number of common stochastic trends in our system of markets. Second, it allows us to determine the speed of various market adjustments to the long-run equilibrium path(s) as well as explicitly test for weak exogeneity of specific markets in the long-run. Third, because cointegration analysis requires levels of time series we are able to avoid the loss of efficiency and specification biases, which characterize the use of differences. Finally, the finding of cointegration provides the foundation for the corresponding error correction representation, which forms the basis of the conditional submodel.

Johansen (1992) and Johansen and Juselius (1992) demonstrate that in the context of cointegration we can formally test for weak exogeneity in our long-run parameters by imposing restrictions on the $\alpha_{i j} s, j=1 \cdots r$. Johansen and Juselius (1990) show that for some $i, \alpha_{i}=0, \Delta X_{i t}$ is weakly exogenous for $\alpha$ and $\beta$ in the sense that the conditional distribution of $\Delta X_{t}$ given $\Delta X_{i t}$ and lagged values of $X_{t}$ contains the parameters of $\alpha$ and $\beta$ while the distribution of $\Delta X_{i t}$ given lagged values of $X_{t}$ does not. To test this hypothesis, restrict $\alpha_{i j}=0$, and solve the model under this restriction. Comparison of the restricted model with the unrestricted model using the likelihood ratio procedure given by Johansen (1992) produces the following test statistic:

$$
-2 \ln Q\left(\mathrm{H}_{\mathrm{R}} \mid \mathrm{H}_{\mathrm{UR}}\right)=T \ln \left[\frac{\prod_{j=1}^{r}\left(1-\lambda_{j}^{\mathrm{H}_{\mathrm{R}}}\right)}{\prod_{j=1}^{r}\left(1-\lambda_{j}^{\mathrm{H}_{\mathrm{UR}}}\right)}\right]
$$

\footnotetext{
${ }^{2}$ We are indebted to Kenneth Kasa for making these data available to us.
} 
where $T=$ number of observations, $\lambda_{j}^{\mathrm{H}_{\mathrm{UR}}}=$ the eigenvalues corresponding to the $r$ cointegrating vectors in the full model and $\lambda_{j}^{\mathrm{H}_{\mathrm{R}}} 0=$ the eigenvalues corresponding to the $r$ cointegrating vectors in the restricted model. The critical value is $\chi^{2}$ distributed with $r$ degrees of freedom.

\subsection{Superexogeneity}

Once cointegration is established, the legitimacy of a valid ECM is likewise established. This ECM forms the basis of the conditional model that is then used as the foundation for superexogeneity tests.

Consider the joint distribution of two variables, $x_{t}$ and $y_{t}$, which are assumed conditionally normal with the following conditional means:

$$
\begin{aligned}
& E\left[x_{t} \mid \omega_{t}\right]=\mu_{t}^{x}, \\
& E\left[y_{t} \mid \omega_{t}\right]=\mu_{t}^{y},
\end{aligned}
$$

and variance-covariance matrix, ${ }^{3}$

$$
\sum=\left[\begin{array}{ll}
\sigma^{x x} & \sigma^{y x} \\
\sigma^{x y} & \sigma^{y y}
\end{array}\right]
$$

$E($.$) is the expected value operator and \omega$ is the information set which is assumed to contain past values of both $x$ and $y$ and current and past values of other conditioning variables $z$.

Let the conditional expectation of $y$ on $x$ be represented as:

$$
E(y \mid x)=\delta\left(x-\mu^{x}\right)+\mu^{y}, y-E(y \mid x)=\eta .
$$

Noting that $\delta$ is the regression coefficient of $y$ on $x$, the conditional variance is given by:

$$
\operatorname{var}(\eta)=\operatorname{var}[y-E(y \mid x)]=\sigma^{y y}-\frac{\left(\sigma^{y x}\right)^{2}}{\sigma^{x x}},
$$

where we have replaced $\delta$ by its definition.

Thus a model which is based on the conditional means of $y$ and $x$ can be represented as

$$
E(y \mid \omega)=\beta E(x \mid \omega)+z^{\prime} \gamma,
$$

Using Eqs. (4) and (6) the following conditional model is obtained:

$$
y=\beta x+z^{\prime} \gamma+(\delta-\beta)\left(x-\mu^{x}\right)+\eta,
$$

\footnotetext{
${ }^{3}$ The time subscript, $t$, is dropped for convenience.
} 
which reduces to the conventional regression model

$$
y=\beta x+z^{\prime} \gamma+\eta,
$$

if the three conditions outlined in Section 3, namely weak exogeneity of $x$, consistency of parameter estimates and invariance are met. This basic model is derived from the ECM in a system of cointegrated variables.

In arriving at an expression that can be used to test for superexogeneity, Engle and Hendry (1993) examine the impact of the changes in the moments of $x$ on $\beta$ and allow $\Sigma$ (the variance-covariance matrix) to be time varying. Using a linear expansion they obtain the following two expressions:

$$
\begin{aligned}
\beta= & \beta_{0}+\beta_{1} \mu^{x}+\beta_{2} \sigma^{x x}+\beta_{3}\left(\sigma^{x x} / \mu^{x}\right), \\
& \sigma^{y x} / \sigma^{x x}=\delta=\delta_{0}+\delta_{1} \sigma^{x x} .
\end{aligned}
$$

After suitable substitutions, the following test regression for superexogeneity is obtained:

$$
\begin{aligned}
y= & \beta_{0} x+z^{\prime} \gamma+\left(\delta_{0}-\beta_{0}\right)\left(x-\mu^{x}\right)+\delta_{1}\left(x-\mu^{x}\right) \sigma^{x x} \\
& +\beta_{1}\left(\mu^{x}\right)^{2}+\beta_{2} \mu^{x} \sigma^{x x}+\beta_{3}\left(\sigma^{x x}\right)+\epsilon .
\end{aligned}
$$

\section{Cointegration results}

The initial step in testing for cointegration is to test for the presence of unit roots in each country's stock price index. Two tests are performed using the Augmented Dickey-Fuller test. The first tests for the presence of a unit root with zero trend in the series, while the second tests for the presence of a unit root with a non-zero linear trend. Results are reported in Table 1. In both cases, the null hypothesis cannot be rejected, indicating the presence of a unit root with a trend in each stock index.

Given the presence of a unit root in each stock market we proceed with Johansen's method in testing for the presence of cointegration among the four

Table 1

Adjusted Dickey (ADF)(12) Fuller statistics

\begin{tabular}{lll}
\hline & Without trend* & With trend** \\
\hline GER & -1.4717 & -2.0052 \\
JP & -1.6914 & -2.1784 \\
UK & -0.5481 & -1.8187 \\
US & -0.9340 & -1.5716 \\
\hline
\end{tabular}

$* 95 \%$ critical value $=-2.8770$.

$* * 95 \%$ critical value $=-3.4347$. 
Table 2

Johansen test for cointegration among US, JP, GER and UK ${ }^{\mathrm{ab}}$

\begin{tabular}{|c|c|c|c|c|c|c|}
\hline \multirow[t]{2}{*}{ Panel A } & \multicolumn{6}{|c|}{ Eigenvalues $(k=2)$} \\
\hline & 0.16847 & 0.058665 & 0.016968 & $0.6222 \mathrm{E}-3$ & & \\
\hline \multicolumn{7}{|l|}{ Panel B } \\
\hline \multirow[t]{2}{*}{ Null } & \multirow[t]{2}{*}{$\lambda$-max } & \multirow[t]{2}{*}{ Trace } & \multicolumn{2}{|c|}{$\begin{array}{l}\text { Critical value } \\
\lambda \text {-max }\end{array}$} & \multicolumn{2}{|l|}{ Trace } \\
\hline & & & $95 \%$ & $90 \%$ & $95 \%$ & $90 \%$ \\
\hline$r=0$ & 36.53 & 52.01 & 27.07 & 24.73 & 47.21 & 43.95 \\
\hline$r \leq 1$ & 11.97 & 15.48 & 20.97 & 18.60 & 29.67 & 26.79 \\
\hline$r \leq 2$ & 3.39 & 3.52 & 14.07 & 12.07 & 15.41 & 13.33 \\
\hline$r \leq 3$ & 0.12 & 0.12 & 3.76 & 2.69 & 3.76 & 2.69 \\
\hline
\end{tabular}

${ }^{\mathrm{a}}$ Trend maintained.

${ }^{\mathrm{b}} k$ refers to the number of lags.

national stock markets. Results are presented in Table 2 . Evidence from both the ' $\lambda$ max' and 'Trace' statistics indicates that there is only one cointegrating vector. ${ }^{4}$ In his analysis of the number of common stochastic trends in national equity markets, Kasa (1992), using five stock indices and monthly data obtained one cointegrating vector, results similar to those reported here. However, using quarterly data he obtained four cointegrating vectors. Given that we are testing whether the ECM embodies forward-looking expectations we base our analysis on the results obtained using the higher frequency monthly data.

The finding of one cointegrating vector indicates that there are three common stochastic trends. Although a formal international asset pricing model is not being tested, it is possible to attach some interpretation to the cointegrating vector and the stochastic trends. As Kasa (1992) points out, the cointegrating vector can be interpreted as a composite of the stationary components characterizing the earnings/dividends streams and of the temporary departure from the present value relationship brought about by time varying discount rates and national risk premia. Two of the three stochastic trends may represent domestic and international stochastic growth components driving earnings and dividends. In other words, they may capture market reactions to a domestic and international business cycle component. It is important to note that by converting each index into real US dollars we have introduced a stochastic trend into the system. Thus, the remaining stochastic trend may be representing the effect(s) of stochastic exchange rates.

The eigenvectors and weights are presented in Table 3 , with the results of weak exogeneity tests reported in Table 4 . The weights are the estimated $\alpha$ coefficients and can be interpreted as the average speed of adjustment of each series towards

\footnotetext{
${ }^{4}$ This result is consistent across multiple VAR lag structures. However, two lags produce an error series that is white noise and minimize the AIC criterion.
} 
Table 3

The estimated cointegrated vectors partioned into the stationary components $\left(\beta_{1}\right)$ and its weights $\left(\alpha_{1}\right)$ together with the remaining eigenvectors $\left(v_{1}, v_{2}, v_{3}\right)$ and the corresponding weights $\left(w_{1}, w_{2}, w_{3}\right)$

\begin{tabular}{|c|c|c|c|c|}
\hline \multirow[t]{2}{*}{ Panel A } & \multicolumn{4}{|c|}{ Eigenvectors } \\
\hline & $\beta_{1}$ & $v_{1}$ & $v_{2}$ & $v_{3}$ \\
\hline US & -1.000 & -1.000 & -1.000 & -1.000 \\
\hline JP & 0.590 & -0.172 & 1.809 & -1.835 \\
\hline GER & 0.518 & 0.321 & -3.862 & -1.298 \\
\hline UK & -1.137 & 0.597 & 0.117 & -1.323 \\
\hline \multirow[t]{2}{*}{ Panel B } & \multicolumn{4}{|l|}{ Weights } \\
\hline & $\alpha_{1}$ & $w_{1}$ & $w_{2}$ & $w_{3}$ \\
\hline US & 0.075 & 0.034 & 0.004 & $0.214 \mathrm{E}-3$ \\
\hline JP & 0.008 & -0.010 & -0.002 & $0.627 \mathrm{E}-3$ \\
\hline GER & 0.057 & -0.076 & 0.004 & $0.245 \mathrm{E}-3$ \\
\hline UK & 0.189 & -0.017 & -0.002 & $0.228 \mathrm{E}-3$ \\
\hline
\end{tabular}

the estimated equilibrium state. As such, a large coefficient reflects a high speed of adjustment. The coefficients seem to indicate that the cointegrating vector is most important for the UK equation and least important for the JP equation. This probably reflects the relative openness of the respective markets. Furthermore, although the dimensions of our systems differ from that estimated in the work by Kasa (1992) and thus may not be directly comparable, the results are broadly consistent. Kasa, in extracting the common trend from his system of five markets, finds that it is most important for Japan. This is consistent with our finding that the cointegrating vector is least important for the Japanese market since the common stochastic trend(s) lie in the orthogonal complement of the cointegrating space (see Kasa, 1992 for further discussion).

Johansen and Juselius (1992) point out that the eigenvalues reflect the extent to which the eigenvector is correlated with the stationary part of the process. Thus the finding that the eigenvector is most important for the UK market, suggests that relative to the other markets the UK market is most correlated with the stationary part of the process.

Table 4

The eigenvalues under the unrestricted model $\left(\mathrm{H}_{\mathrm{UR}}\right)$ and the restricted model $\left(\mathrm{H}_{\mathrm{R}}\right)$ and the calculated test statistics

\begin{tabular}{|c|c|c|c|c|c|}
\hline \multirow{2}{*}{$\begin{array}{l}\text { Hypothesis } \\
\mathrm{H}_{\mathrm{UR}}:-\end{array}$} & \multirow{2}{*}{$\begin{array}{l}\text { Test-statistic } \\
-\end{array}$} & \multicolumn{4}{|c|}{ Eigenvalue } \\
\hline & & 0.1685 & 0.0587 & 0.0170 & 0.0006 \\
\hline $\mathrm{H}_{\mathrm{R}}$ : Japan weakly exogenous & 9.3234 & 0.0732 & 0.0361 & 0.0024 & \\
\hline $\mathrm{H}_{\mathrm{R}}$ : Germany weakly exogenous & 5.9393 & 0.1090 & 0.0320 & 0.0007 & \\
\hline $\mathrm{H}_{\mathrm{R}}:$ UK weakly exogenous & 9.0011 & 0.0767 & 0.0118 & 0.0003 & \\
\hline
\end{tabular}

Note: The test statistic is distributed $\chi^{2}(1)$. The $95 \%$ critical value is 3.84 . 
To formally test for the 'importance' of the long-run relation in each market, the long-run weak exogeneity test described in Section 4 is performed. The eigenvalues corresponding to the restricted models (as well as those of the full model) are presented in Table 4 along with the calculated test statistics. Our test statistic, being $\chi^{2}(1)$, is significant for every restriction. This result is consistent with the hypothesis that none of the markets are weakly exogenous in the long-run although the sensitivity of the markets to the long-run equilibrium path obviously varies (with the German market coming the closest). Furthermore, it foreshadows rejection of superexogeneity.

Finally, the estimate of the long-run impact matrix, which measures the effect of the cointegrating relationship in each of the four markets, is presented in Table 5. The evidence indicates that the UK market is the most responsive to the system, while the Japanese market is the least responsive, with the remaining two markets being intermediate. Again, this probably reflects the relative openness of the markets being investigated.

In summary, the results indicate that there is a single long-run equilibrium relationship to which all markets are sensitive. The existence of a long-run relationship between the national stock markets of the four largest industrialized countries has important implications for international asset allocations. Specifically, the presence of cointegration suggests that the claimed benefits of international portfolio diversification may be substantially overstated. Additionally, it is consistent with the conjecture that the differencing of data may lead to the removal of important information thus leading to incorrect inferences.

\section{Superexogeneity results}

In order to test for superexogeneity it is necessary to specify the ECM that is implied by the cointegration results of the previous section. The parsimonious ECM was obtained by engaging in general to specific modeling procedure. Results are shown in Eq. (11) below, with $t$-statistics in parentheses.

$$
\begin{aligned}
\Delta \mathrm{US}= & \underset{(3.17)}{0.036}+\underset{(1.23)}{0.063} \Delta \mathrm{JP}_{t-1}+\underset{(5.23)}{0.228} \Delta \mathrm{UK}_{t}+\underset{(3.29)}{0.177} \Delta \mathrm{GER}_{t} \\
& -\underset{(-1.29)}{0.081} \Delta \mathrm{US}_{t-1}+\underset{(3.38)}{0.062 \mathrm{ECT}_{t}}
\end{aligned}
$$

Table 5

Estimated long-run impact matrix

\begin{tabular}{lrrrr}
\hline Equation & \multicolumn{1}{l}{ US } & \multicolumn{1}{l}{ JP } & GER & \multicolumn{1}{c}{ UK } \\
\hline 1 & -0.075 & 0.044 & 0.039 & -0.085 \\
2 & -0.008 & 0.005 & 0.004 & -0.009 \\
3 & 0.017 & -0.013 & -0.008 & 0.009 \\
4 & -0.189 & 0.115 & 0.098 & -0.215 \\
\hline
\end{tabular}


$\bar{R}^{2}=0.36 ; F_{5,192}=21.478 ; \mathrm{DW}=1.860 ; \sigma=0.04 ;$ Serial Correlation: $\chi^{2}(12)=$ 17.228; Reset: ${ }^{5} \chi^{2}(1)=2.335$.

In Eq. (11) $\Delta$ represents a first difference and the error correction term $\left(\mathrm{ECT}_{t}\right)$ is the residual from the cointegrating equation. The equation shows that contemporaneous changes (returns) in both the UK and German stock markets are statistically significant in explaining the variation in changes (returns) of the US stock market. It is important to note that it is the contemporaneous value of ECT that is significant in Eq. (11). Lagged values were also tried but these were statistically insignificant. These results provide the first evidence consistent with the hypothesis that the equilibrium error results from agents' forecast of changes, rather than partial adjustment of the US market to the changes in the remaining stock markets. Specifically, the error correction term is consistent with financial market participants' contemporaneous recognition of errors in their forecasts of expected future market returns. However, caution must be exercised in attaching too much significance to this interpretation. Specifically, because we use monthly data it is also possible that the contemporaneous ECT implies partial adjustment within the periodicity of the data, rather than forward-looking behavior. ${ }^{6}$ These results are similar to those found by Bairdsen (1992) in modeling Norwegian money demand. He interprets these contemporaneous terms as immediate effects of responses to the associated variables and notes that the economic interpretation (such as noted above) should guide empirical model building. Finally, the diagnostic tests would seem to indicate that the ECM is reasonably well-specified. ${ }^{7}$

Although Eq. (11) appears to be stable, there have been several potential regime shifts and exogenous shocks over the sample period. To implement the remaining superexogeneity tests for the US stock market outlined in Section 3, marginal models of the variables (excluding $\mathrm{ECT}_{t}$ ) included in the ECM must be constructed. To incorporate some of these possible regime shifts and exogenous shocks in the marginal models, several dummy variables were created and included in the regressions. The choice of dummy variables is based on previous empirical work and the fact that the methodology requires control for all possible structural changes. ${ }^{8}$ Potential regime changes included: the 1974 oil embargo (OIL); the 1976 IMF meeting in Jamaica in which the floating exchange rate mechanism is 'legalized' (JAM); the creation of the EMS in 1979 (EMS); the unprecedented increase in the value of the US dollar over the period 1980-1985 (US\$); the debt crisis of 1982 (DBT); the Plaza Accord of 1985 (PA85); the 'big bang' in England in 1986 (BBUK); the stock market crash in 1987 (SMKT); the Louvre accord in 1987 (LA87); and the agreement in 1984 between Japan and the US that Japan's financial markets would be further deregulated (JP84).

\footnotetext{
${ }^{5}$ This is Ramsey's test for parameter stability over the sample period.

${ }^{6} \mathrm{We}$ thank an anonymous reviewer for pointing this out to us.

${ }^{7}$ Cusum and cusum-squared tests on the regression residuals reinforce this conclusion.

${ }^{8}$ Clearly we have included numerous dummy variables in our analysis. However, our list is by no means exhaustive. For a complete list of potential regime changes see the discussion by Mussa and Goldstein (1993).
} 
Table 6

Marginal models for explanatory variables of US stock market equation

(1) Marginal model for UK stock market:

$$
\begin{aligned}
& \Delta \widehat{\mathrm{UK}}_{t}=\underset{(-0.15)}{-0.002}-\underset{(-0.35)}{0.022} \Delta \mathrm{UK}_{t-1}+\underset{(3.21)}{0.448} \Delta \mathrm{GER}_{t}+\underset{(3.21)}{0.274} \Delta \mathrm{JP}_{t}+\underset{(2.39)}{0.048 \mathrm{JAM}}+\underset{(1.28)}{0.026 \mathrm{PA} 85} \\
& +\underset{(1.64)}{0.037 \mathrm{SMKT}}-\underset{(-4.42)}{0.131} \mathrm{OIL}-\underset{(-2.22)}{0.061} \mathrm{BBUK}
\end{aligned}
$$

$\bar{R}^{2}=0.30 ; F_{8,189}=11.29$

(2) Marginal model for the German stock market:

$$
\begin{aligned}
\Delta \widehat{\mathrm{GER}} t= & \underset{(0.62)}{0.006}-\underset{(-1.15)}{0.075} \Delta \mathrm{GER}_{t-1}+\underset{(5.35)}{0.285} \Delta \mathrm{UK}_{t}+\underset{(3.23)}{0.285} \Delta \mathrm{JP}_{t}-\underset{(-2.94)}{0.031} \mathrm{DBT}-\underset{(2.37)}{0.025 \mathrm{US} \$} \\
& -\underset{(-1.20)}{0.022} \mathrm{SMKT}-\underset{(-1.74)}{0.033} \mathrm{OIL}+\underset{(2.50)}{0.046 \mathrm{BBUK}} \\
\bar{R}^{2}=0.26 & F_{8,189}=9.67
\end{aligned}
$$

(3) Marginal model for the Japanese stock market:

$$
\begin{aligned}
& \Delta \widehat{\mathrm{JP}}_{t}=\underset{(1.13)}{0.023}+\underset{(0.44)}{0.295} \Delta \mathrm{JP}_{t-1}+\underset{(3.75)}{0.208} \Delta \mathrm{UK}_{t}+\underset{(2.97)}{0.215 \Delta \mathrm{GER}_{t}}-\underset{(-2.56)}{0.055} \mathrm{PA} 85-\underset{(-1.57)}{0.025 \mathrm{DBT}} \\
& \quad \underset{(-1.29)}{0.024 \mathrm{JP} 84}+\underset{(2.93)}{0.054 \mathrm{BBUK}} \\
& \\
& \bar{R}^{2}=0.22 ; F_{7,190}=8.64
\end{aligned}
$$

The estimated marginal models are reported in Table 6. The selection of the variables and the number of lags included in the estimated models are based on the general to specific methodology of Hendry and Richard (1982). The statistical significance of the various dummy variables in the marginal models indicates that important regime shifts occurred over the sample period investigated. Of interest is the finding that the dummy variable representing the Big Bang in the UK is significant in all the marginal models. This is consistent with the results reported by Masulis and $\mathrm{Ng}$ (1995). The insignificance of the dummy variable representing the 1987 stock market crash in all the marginal models is consistent with the results of King et al. (1994) which show that the effect of the crash was temporary. This simply confirms what a graph of the data strongly suggests, that the 1987 crash did not have permanent effects. Why beliefs to the contrary have persisted in the finance literature is rather inexplicable.

In general, the results demonstrate that the Japanese market was the least affected by the various changes that occurred over the sample period. Significance of the Plaza dummy in this equation may be capturing the effect of the accelerated liberalization, which was occurring in the Japanese financial markets, rather than the impact of the exchange rate coordination. This is consistent with the earlier results that indicated that the Japanese market was the most isolated. In contrast, the marginal model for the UK stock market has the highest explanatory power for changes in the UK stock market. This result is likewise consistent with results of the previous section. 
The marginal models presented in Table 6 are used to obtain proxies for the first two conditional moments of $\Delta \mathrm{UK}, \Delta \mathrm{JP}$ and $\Delta \mathrm{GER}$. The variables $\Delta \widehat{\mathrm{UK}}, \Delta \widehat{\mathrm{JP}}$ and $\Delta \widehat{\mathrm{GE}}$ are used as proxies for the conditional mean of each series. Residual based tests from the marginal models indicate only weak presence of ARCH effects. As a result, a three-period moving average of the squared residuals from the marginal models was used as proxies for the conditional variances denoted as $\sigma_{U K}^{2} \sigma_{J P}^{2} \sigma_{G E R}^{2}$. Following the procedure outlined in Section $4, \Delta \mathrm{UK}-\Delta \widehat{\mathrm{UK}}$ is used to test for weak exogeneity; $\sigma_{U K}^{2}, \Delta \widehat{\mathrm{UK}}^{2}$ and $\Delta \widehat{\mathrm{UK}} \sigma_{U K}^{2}$ are used to test for invariance; and $\sigma_{U K}^{2}(\Delta \mathrm{UK}-\Delta \overline{\mathrm{UK}})$ is used to test for parameter constancy. Each variable is introduced in Eq. (11) and then tested for significance. This procedure is also performed for both $\Delta \mathrm{JP}$ and $\Delta \mathrm{GER}$. The corresponding $F$-statistics are reported in Table 7.

Table 7 shows that the variables testing for invariance of the parameters is statistically significant at conventional levels for both the British and Japanese equity markets but not for the German stock market. These results provide evidence that the conditional variance for these markets (Japan and UK) takes distinct values across different regimes, thus leading to non-constancy of parameters. Thus we can reject superexogeneity of the Japanese and the British equity markets quite comfortably. Based on results from the marginal models, the rejection of superexogeneity for Japan is in all likelihood due to rejection of invariance resulting from the Big Bang and acceleration of domestic market liberalization. The Big Bang and oil embargo account for rejection of invariance, hence superexogeneity, for the UK market. Furthermore, the fact that the German stock market is weakly exogenous and invariant according to these tests, probably

Table 7

Single variable superexogeneity tests for the UK, JP and GER markets

\begin{tabular}{ll}
\hline$\Delta \mathrm{UK}-\Delta \widehat{\mathrm{UK}}$ & $F_{1,189}=0.0008$ \\
$\Delta \mathrm{GER}-\Delta \widehat{\mathrm{GER}}$ & $F_{1,189}=0.0001$ \\
$\Delta \mathrm{JP}-\Delta \widehat{\mathrm{JP}}$ & $F_{1,189}=0.3961$ \\
$\sigma_{U K}^{2}$ & $F_{1,189}=0.0228$ \\
$\sigma_{{ }^{2}}^{2}$ & $F_{1,189}=0.0568$ \\
$\sigma_{J P}^{2}$ & $F_{1,189}=1.9930$ \\
$(\Delta \mathrm{UK}-\Delta \widehat{\mathrm{UK}}) \sigma_{U K}^{2}$ & $F_{1,189}=0.0420$ \\
$(\Delta \mathrm{GER}-\Delta \widehat{\mathrm{GER}}) \sigma_{G E R}^{2}$ & $F_{1,189}=1.4000$ \\
$(\Delta \mathrm{JP}-\Delta \widehat{\mathrm{JP}}) \sigma_{J P}^{2}$ & $F_{1,189}=0.0491$ \\
$\Delta \widehat{\mathrm{UK}}^{2}$ & $F_{1,189}=4.8926$ \\
$\Delta \widehat{\mathrm{GER}}^{2}$ & $F_{1,189}=0.0568$ \\
$\Delta \widehat{\mathrm{JP}}^{2}$ & $F_{1,189}=3.4030$ \\
$\Delta \widehat{\mathrm{UK}}^{2}{ }_{U K}$ & $F_{1,189}=9.8273$ \\
$\Delta \widehat{\mathrm{GER}} \sigma_{G E R}^{2}$ & $F_{1,189}=0.0804$ \\
$\Delta \widehat{\mathrm{JP}}^{2}{ }_{J P}$ & $F_{1,189}=2.6701$
\end{tabular}


reflects the fact that over much of the sample period German stocks have not played a major role in US investors' asset allocations. These results are generally consistent with the Korajczyk and Viallet (1992) finding that regime changes affect asset pricing.

The finding that the variables which test for weak exogeneity are not significant at conventional statistical levels is surprising given that our results from the cointegration analysis indicated that the variables were not weakly exogenous. However, in a recent study, Psaradakis and Sola (1996) using Monte Carlo simulation demonstrate that of the three tests for superexogeneity, the tests for weak exogeneity are the least powerful. They conclude that the rejection frequency of tests for the hypothesis of superexogeneity is therefore dramatically reduced. Thus the fact that we indeed reject superexogeneity of both the UK and Japanese markets attests to the strength of our findings.

In summary, these results in conjunction with the rejection of weak exogeneity from the cointegration analysis, for all markets necessitate rejecting superexogeneity for the markets investigated. More importantly, the rejection of superexogeneity suggests that US investors in forming international portfolios form (near) rational expectations. That is, US investors in determining their asset allocations internationally, incorporate expectations of future economic changes. However, in that the error correction term in the conditional submodel is significant and generally non-zero, future expectations are not unbiased.

\section{Conclusion}

In this article we have hypothesized a different interpretation of the evidence of cointegration between a system of national equity markets. Specifically, we argued that the common interpretation that cointegration between economic variables reflect (partial) adjustment to some past disequilibria may not be applicable to a system of national stock markets. Instead, it is quite feasible that investors form (near) rational expectations. Thus error correction models and cointegration may arise because of agents' forecasts of economic changes. Using the framework suggested by Engle and Hendry (1993) to test for superexogeneity, our results suggest that the adjustment to the long-run path indicated by the presence of cointegration among the four national equity markets is shaped by economic agents' forecasts of changes in these equity markets.

Specifically, we find that our system of markets possesses one long-run equilibrium path and that all markets are endogenous in this long-run relationship. In the dynamic adjustment model, our results are consistent with invariance of the German market. Nonetheless, the rejection of weak exogeneity of all markets in the long run necessitates rejection of superexogeneity for the entire system of variables.

These results imply that our system of national equity markets is indeed a forward construct expectations based models. This conclusion gives credence to the broad class of expectations based models which form the foundation of financial 
modeling. Additionally, the results imply that agents participating in these markets may thwart policies designed to influence international financial flows. However, given that the parameters of interest are not all variation free across regimes, the nature of the relationships that characterize equity asset pricing models are altered by policy activity. Therefore the Lucas critique has relevance to equity market control efforts. Additionally, the rejection of invariance is consistent with the notion that the most basic assumption of stability of the demand function for stocks may be inappropriate for certain sample periods.

\section{Acknowledgements}

We are grateful to seminar anticipants at Arizona State University, two anonymous referees and the Editor James Lothian for comments that substantially improved this article.

\section{References}

Bairdsen, G., 1992. Dynamic modeling of the demand for narrow money in Norway. J. Policy Model. 14, 363-393.

Bekaert, G., Harvey, C.R., 1995. Time-varying world market integration. J. Finance 50, 403-444.

Campbell, Y., Hamao, Y., 1992. Predictable stock returns in the United States and Japan: a study of long-term capital market integration. J. Finance 47, 43-69.

Campbell, J., Shiller, R., 1988. Interpreting cointegrated models. J. Econ. Dyn. Control 12, 505-522.

Chan, K., Karolyi, A., Stultz, R., 1992. Global financial markets and the risk premium on US equity. J. Financ. Econ. 32, 137-167.

Dow, J., Gorton, G., 1995. Stock Markets Efficiency and Economic Efficiency: Is There a Connection. NBER Working Paper No. 5233, Cambridge, Ma.

Engle, R., Hendry, D., 1993. Testing superexogeneity and invariance. J. Econ. 56, 119-139.

Engle, R., Hendry, D., Richard, J., 1983. Exogeneity. Econometrica 51, 277-304.

Eun, C., Shim, S., 1989. International transmission of stock market movements. J. Financ. Quant. Anal. 24, 241-256.

Hamao, Y., Masulis, R., Ng, V., 1990. Correlation price changes and volatility across international stock markets. Rev. Financ. Stud. 3, 281-307.

Hendry, D., Richard, J., 1982. On the formation of empirical models in dynamic econometrics. J. Econom. 20, 3-33.

Hurn, A.S., Muscatelli, V.A., 1992. Testing superexogeneity: the demand for broad money in the UK. Oxf. Bull. Econ. Stat. 54, 543-556.

Jeon, B.N., von Furstenberg, G., 1990. Growing international co-movement in stock price indexes. Q. Rev. Econ. Bus. 30, 15-30.

Johansen, S., 1992. Testing weak exogeneity and the order of cointegration in UK money demand data. J. Policy Model. 14, 313-334.

Johansen, S., 1988. Statistical analysis of cointegration vectors. J. Econ. Dyn. Control 12, 231-254.

Johansen, S., Juselius, K., 1990. Maximum likelihood estimation and interference on cointegration with applications to the demand for money. Oxf. Bull. Econ. Stat. 52, 169-210.

Johansen, S., Juselius, K., 1992. Testing structural hypothesis in a multivariate cointegration analysis of the PPP and UIP for the UK. J. Econom. 53, 211-244.

Kasa, K., 1992. Common stochastic trends in international stock markets. J. Monet. Econ. 29, 95-124. 
King, M., Sentana, E., Wadhwani, S., 1994. Volatility and links between national stock markets. Econometrica 62, 901-933.

Korajczyk, R., Viallet, C., 1992. Equity risk premia and the pricing of foreign exchange risk. J. Econom. 33, 199-220.

Leachman, L., Francis, B.B., 1995. Long run relations among the G-5 and G-7 equity markets: evidence on the plaza and louvre accords. J. Macroecon. 17, 551-578.

Longin, F., Solnik, B., 1995. Is the correlation in international equity returns constant: 1960-1990? J. Int. Money Finance 14, 3-26.

Lucas, R.E., Jr., 1976. Econometric policy evaluation: a critique. In: Brunner, K., Meltzer, A. (Eds.), Camegie-Rochester Conferences on Public Policy, vol. 1, pp. 19-46, Supplementary Series to the J. Monet. Econ., North-Holland Publishing Co., Amsterdam.

Marsh, T., Merton, R., 1987. Dividend behavior for the aggregate stock market. J. Bus. 60, 1-40.

Masulis, R., Ng, V., 1995. Overnight and daytime stock return dynamics on the London stock exchanges: the impacts of 'big bang' and the 1987 stock-market crash. J. Bus. Econ. Stat. 13, 365-378.

Mussa, M., Goldstein, M., 1993. The Integration of World Capital Markets. Changing Capital Markets: Implications for Monetary Policy, Federal Reserve Bank of Kansas City, Kansas City, Mo., pp. 245-313.

Nickell, S., 1985. Error correction partial adjustment and all that: an expository note. Oxf. Bull. Econ. Stat. $47,119-130$.

Wheatly, S., 1988. A critique of latent variable tests of asset pricing models. J. Financ. Econ. 23, 325-338.

Psaradakis, Z., Sola, M., 1996. On the power of tests for superexogeneity and structural invariance. 72 $151-175$. 